Table 1. Reaction conditions, conversions, and product molecular weights for the polymerization of selected organodichlorosilanes $\left(\mathrm{R}^{1} \mathrm{R}^{2} \mathrm{SiCl}_{2}\right)$.

Polysilane
$\mathrm{R}^{1}, \mathrm{R}^{2}$

$$
\mathrm{R}^{1}, \mathrm{R}^{2}
$$

$\mathrm{Me}, \mathrm{Ph}$

$\mathrm{Me}, \mathrm{Ph}$

$\mathrm{Me}, \mathrm{Ph}$

$\mathrm{Me}, \mathrm{Ph}$

$\mathrm{Ph}, \mathrm{Ph}$

$\mathrm{Ph}, \mathrm{Ph}$

$\mathrm{Ph}, \mathrm{p}$-Tol

$\mathrm{Me}, p$-Tol

$\mathrm{Me}, p$-Tol

$\mathrm{Me}, p$-Tol

n-Hex n-Hex Ether

$\begin{array}{ccc}\begin{array}{c}\text { Crown } \\ \text { ether }\end{array} & \begin{array}{c}\text { Conversion } \\ (\%)\end{array} & M_{\mathrm{w}} \\ \text { No } & 11 & 9690 \\ \text { Yes } & 26 & 9510 \\ \text { No } & 8 & 3700 \\ \text { Yes } & 99\left(55^{\mathrm{b}}\right) & 65950 \\ \text { No } & 36 & \\ \text { Yes } & 81 & \\ \text { Yes } & 40 & \\ \text { Yes } & 8 & 4340 \\ \text { No } & 1 & 3400 \\ \text { Yes } & 66\left(25^{\mathrm{b}}\right) & 7030 \\ \text { Yes } & 22\left(9^{\mathrm{b}}\right) & 23800\end{array}$

${ }^{\mathrm{a}} p$ - $\mathrm{Tol}=p-\mathrm{MeC}_{6} \mathrm{H}_{4} ; \mathrm{n}-\mathrm{Hex}=\mathrm{n}$-hexyl. ${ }^{\mathrm{b}}$ Yield taken from reference 1 for syntheses in toluene without any additive.

$$
n \mathrm{R}^{1} \mathrm{R}^{2} \mathrm{SiCl}_{2}+2 n \mathrm{Na} \underset{\text { reflux }}{\stackrel{\text { toluene }}{\longrightarrow}}\left[-\mathrm{SiR}^{1} \mathrm{R}^{2}-\right]_{n}+2 n \mathrm{NaCl}
$$

Scheme 1

consequence the yields of desired polymer are usually only in the region of $9-55 \%^{1}$ and are difficult to reproduce. Recently it has been shown $n^{5,6}$ that in the presence of catalytic amounts of a crown ether, better reproducibility of polymer yields can be achieved with molecular weight distributions tending to the monomodal. Furthermore, for the polymerisation of dichlorodi-n-heptylsilane in toluene the polymer yield was higher when 15-crown-5 rather than heptane or diglyme was added to the reaction mixture. However, in the case of the polymerization of dichloromethylphenylsilane,$^{5}$ the presence of the crown ether did not alter the proportion of cyclic to polymeric product, even though the yield of the latter was increased to about $60 \%$.
The polymerisations of methylphenyl-, methyltolyl-, diphenyl-, phenyltolyl-, and di-n-hexyl-silane and of diphenylgermane have been investigated to establish the optimum reaction conditions for the formation of high yields of high molecular weight products. The results are given in Table 1 . Molecular weights were determined as polystyrene equivalents in tetrahydrofuran (THF) solution using size exclusion chromatography. In the case of the otherwise intractable polydiarylsilanes and polydiphenylgermane, slight solubility for this purpose was achieved in boiling THF but the resultant data are considered to be unreliable and so are not quoted.

The reactions of dichloromethylphenylsilane with sodium sand in refluxing toluene, in refluxing toluene in the presence of 15 -crown-5, and in refluxing diethyl ether all gave low yields of a low molecular weight polymer. On the other hand the reaction using diethyl ether as the reflux medium in the presence of 15 -crown-5 resulted in an almost quantitative yield of product consisting of $12 \%$ of cyclic material (removed by extraction in hexane) and $88 \%$ of high molecular weight polymer which was readily soluble in THF. Similar trends are observable for the other polymerizations including those of the dichlorodiarylsilanes.

The results suggest that high yields of polysilanes can better be achieved from the interaction of a dichlorosilane and sodium sand in the presence of 15 -crown-5 at the low refluxing temperature attainable using diethyl ether. Polydiphenylgermane was obtained in $74 \%$ yield under these conditions.

\section{Received, 25th April 1990; Com. 0/01841D}

\section{References}

1 R. West, J. Organomet. Chem., 1986, 300, 327.

2 R. D. Miller and J. Michl, Chem. Rev., 1989, 89, 1359.

3 S. Yajima, J. Hayashi, and M. Omori, Chem. Lett., 1975, 931.

4 R. D. Miller, D. Hofer, D. R. McKean, and C. G. Wilson, 'Materials for Microlithography,' American Chemical Society Symposium Series No. 266, Washington, DC, 1984, p. 293.

5 S. Gauthier and D. J. Worsfold, Macromolecules, 1989, 22, 2213.

6 M. Fujino and H. Isaka, J. Chem. Soc., Chem. Commun., 1989, 466.

\title{
Complexes of a New Mononucleating Cage Ligand; Livelier than Sepulchrates?
}

\author{
Josie Hunter,a,b Jane Nelson,a,b Charlie Harding,b Malachy McCann,c and Vickie McKeed \\ a Chemistry Department, Queen's University, Belfast BT7 5AG, UK \\ b Open University, Milton Keynes MK7 6AA, UK \\ c Chemistry Department, St Patrick's College, Maynooth, Ireland \\ d Chemistry Department, University of Canterbury, Christchurch 1, New Zealand
}

$r$. ? new polyaza cryptand $L 1$, easily made by Schiff's base condensation using Group 2 ions, may be "1 i. ismetallated with first transition series ions to give cryptates which electrochemical investigations show to have

The elegant and comprehensive work of Sargeson et al. ${ }^{1}$ on mononucleating cage ligands of the sep-and sar-type is subject to one significant limitation; \{sep (sepulchrate) = $1,3,6,8,10,13,16,19$-octa-azabicyclo[6.6.6]icosane, sar (sarcophagine) $=3,6,10,13,16,19$-hexa-azabicyclo[6.6.6]icosane $\}$. Because the synthesis uses a kinetically inert metal ion as template, subsequent removal of this metal ion presents difficulty. We have developed ${ }^{2}$ a synthetic approach to cryptand ligands, involving the use of kinetically labile template ions, which avoids this difficulty. The $[2+3]$ condensation of the tripod amine tris(2-ethylamino)amine with glyoxal using Group 2 metal ion templates (Scheme 1) 
Table 1. Spectroscopic, magnetic, and electrochemical ${ }^{c . d}$ properties of the cryptates.

$\Pi-\Pi^{*}$ or

charge-transfer bandsg

\section{Compound}

$\left[\mathrm{CaL}^{1}\right]\left(\mathrm{BPh}_{4}\right)_{2}{ }^{\mathrm{h}}(\mathbf{1})$

$\left[\mathrm{MnL}^{1}\right]\left(\mathrm{BPh}_{4}\right)_{2}{ }^{\mathrm{i}}(2)$

$\left[\mathrm{FeL}^{1}\right]\left(\mathrm{BPh}_{4}\right)_{2}{ }^{\mathrm{i}}(\mathbf{3})$

$\left[\mathrm{FeL}^{1}\right]\left(\mathrm{ClO}_{4}\right)_{2}^{\mathrm{j}}(\mathbf{4})$

$\left[\mathrm{CoL}^{1}\right]\left(\mathrm{BPh}_{4}\right)_{2}{ }^{\mathrm{i}}(\mathbf{5})$

$\left[\mathrm{CoL}^{1}\right]\left(\mathrm{ClO}_{4}\right)_{2} \mathrm{j}(\mathbf{6})$

$\left[\mathrm{NiL}^{1}\right]\left(\mathrm{BPh}_{4}\right)_{2}{ }^{\mathrm{i}}(7)$

$\left[\mathrm{CuL}^{1}\right]\left(\mathrm{ClO}_{4}\right)_{2} \cdot 4 \mathrm{H}_{2} \mathrm{O}^{j}(8)$

$\begin{array}{cc}\begin{array}{c}\lambda_{\text {max. }} \\ / \mathrm{cm}^{-1}\end{array} & \begin{array}{c}\varepsilon / \mathrm{dm}^{3} \\ \mathrm{~mol}^{-1} \mathrm{~cm}^{-1}\end{array} \\ 35710 & 1800 \\ 29400 & 930 \\ 23100 & 2300 \\ 17400 & 5600 \\ 23100 & 1500 \\ 17460 & 3800 \\ 26200 & 1900 \\ 26430 & 1600 \\ & \\ 33200 & 1600 \\ 25900 & 1400 \\ 35600 & 2700 \\ 24300 & 2150\end{array}$

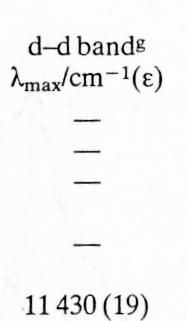

$11100(5)$

$12500(18)$

$15500(120)$

$\begin{array}{cc}293 \mathrm{~K} & 93 \mathrm{~K} \\ \overline{5.99} & -\overline{5.98} \\ 0.95 & 0.40 \\ & \mu / \mu_{\mathrm{B}} \\ \text { Dia. } & \text { Dia. } \\ 4.30 & 4.20 \\ 4.43 & 3.95 \\ 3.04 & 3.01 \\ 1.86 & 1.61\end{array}$

\begin{tabular}{c}
\hline$E^{\mathrm{I} \frac{1}{2}}$ \\
$\mathrm{a}$ \\
$+1350^{\mathrm{b}}$ \\
$+714^{\mathrm{b}}$ \\
+810 \\
+227 \\
$+740^{\mathrm{e}}$ \\
$+131^{\mathrm{f}}$ \\
+1166 \\
+1216
\end{tabular}

$E / m V$

$\begin{array}{lcccc}(\Delta E) & E^{\mathrm{II} \frac{1}{2}} & (\Delta E) & E^{\mathrm{II} \frac{1}{2}} & (\Delta E) \\ & \mathrm{a} & & \mathrm{a} & \\ \text { Irr. } & -987 & 76 & -1276 & 76 \\ \text { Irr. } & -962 & 61 & -1332 & 77 \\ 127 & -983 & 61 & -1349 & 61 \\ 207 & -847 & 87 & -1402 & 87 \\ \text { Irr. } & -815 & 61 & -1371 & 77 \\ \text { Irr. } & -1105 & 61 & -1838 & 91 \\ \text { Irr. } & +282 & 77 & -1197 & 96\end{array}$

${ }^{a}$ No electrochemical activity in this range. ${ }^{b}$ Poorly defined oxidation wave, partly obscured by counterion or solvent process. ${ }^{c}$ Scan rate $50 \mathrm{mV} \mathrm{s}-1 ; E_{\frac{1}{2}}$ ferrocenium/ferrocene $+362 \mathrm{mV}, \Delta E 92 \mathrm{mV}$ vs. AgCl. d $10^{-3} \mathrm{M}$ in dmf, $0.1 \mathrm{M} \mathrm{Et}_{4} \mathrm{NClO}_{4}$. e Anodic component. ${ }^{\mathrm{f}}$ Cathodic component. $\mathrm{g} \mathrm{MeCN}$ solution. h Made by template synthesis at $40-50^{\circ} \mathrm{C}$ in EtOH. ${ }^{\mathrm{i}} \mathrm{Made}$ by transmetallation of $(\mathbf{1})$ or its $\mathrm{Sr}$ analogue with $\mathrm{M}^{2+}(\mathrm{M}=\mathrm{Mn}, \mathrm{Fe}, \mathrm{Co}, \mathrm{Ni}$, or $\mathrm{Cu})$ in $\mathrm{MeCN}-\mathrm{EtOH}$. $^{j}$ Made by anion exchange of $(\mathbf{1})$ with $\mathrm{AgClO}{ }_{4}$ followed by transmetallation with $\mathrm{M}\left(\mathrm{ClO}_{4}\right)_{2}$.

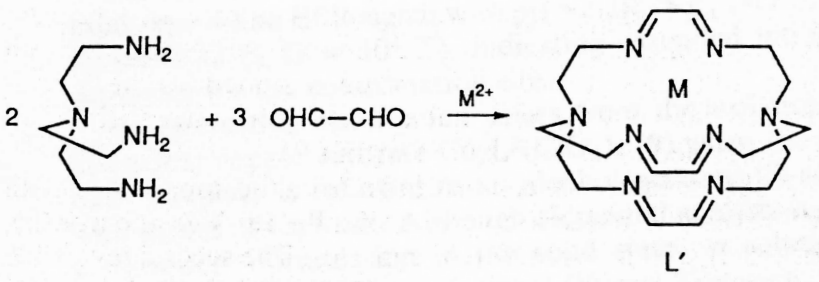

Scheme 1

results in formation of the hexaimino macrobicylic ligand $\mathrm{L}^{1}$ in good yield.

The template ion may then be easily removed by transmetallation with e.g. first transition series ions to give mononuclear complexes (Table 1).

Crystals of $\mathrm{CoL}^{1}\left(\mathrm{ClO}_{4}\right)_{2}$ have been studied by $X$-ray diffraction. The crystals show intimate twinning which precluded accurate determinations of bond lengths and angles; nevertheless the main features of the structure are clear. $\uparrow$ The structure of the cation is shown in Figure 1, the cobalt atom and the two bridgehead nitrogen atoms lie on a crystallographic 3-fold axis. The metal is co-ordinated to all six imino donors (only two of which are crystallographically independent) and has $D_{3}$ symmetry. The Co-N (imine) distances are similar to those in the analogous $[\mathrm{Co}(\mathrm{sep})]^{2+}$ cryptate. ${ }^{3}$ The unco-ordinated bridgehead amino $\mathrm{N}$ lies $\approx 3 \AA$ from the metal ion within a near planar arrangement of adjacent methylene carbons, suggesting near $\mathrm{sp}^{2}$ hybridization of tertiary amine nitrogens, as observed ${ }^{4}$ in $[\mathrm{Ni}(\mathrm{sep})]^{2+}$. The methylene caps are staggered, with a twist angle $\phi$ of $\approx 55^{\circ}$.

The observed disorder-twinning chiefly affects the di-imino links and therefore only tentative conclusions are possible. It appears that these links are oblique rather than parallel. The perchlorate anions lie with one $\mathrm{Cl}-\mathrm{O}$ bond along a 3-fold axis and they do not show any interactions with the cations.

$\dagger$ Solved in the hexagonal space group $P 6_{3}, a=9.164, c=17.185 \AA$, current $R=0.11$. Full details will be published elsewhere.

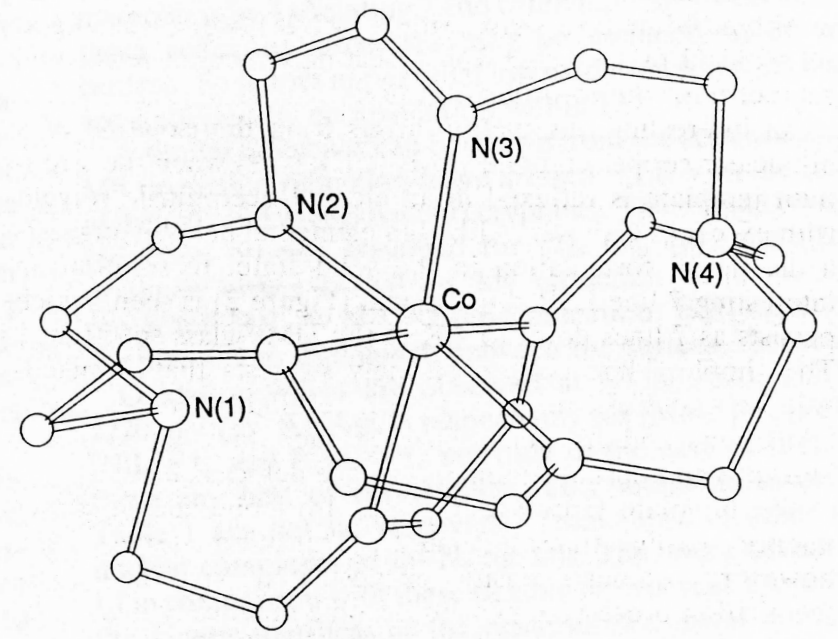

Figure 1. Preliminary crystal structure of $\left[\mathrm{CoL}^{1}\right]^{2+}$.

Although the tail of the broad and intense ligand-to-metal charge transfer (LMCT) absorption dominates the visible region of the electronic spectrum, low intensity bands around 11000 and $12000 \mathrm{~cm}^{-1}$ are, in the case of (5)/(6) and (7), seen and attributed to the lowest energy transition allowed in approximate $O_{h}$ symmetry for $\mathrm{Co}^{\mathrm{II}}$ and $\mathrm{Ni}^{\mathrm{II}}$ respectively. Isomorphous powder patterns for (5) and (7) corroborate the spectral evidence. However (2) and (3) are not isostructural with $(5) /(7)$ nor with each other reflecting presumably the varying influence of ligand field stabilising energy (LFSE) effects in favouring trigonal antiprismatic over the less strained trigonal pyramidal geometry in the order $\mathrm{Fe}^{2+}>$ $\mathrm{Co}^{2+}>\mathrm{Mn}^{2+}$.

All the mononuclear cryptates, as expected, show little temperature-dependence of magnetic moment with evidence of some deviation from regular octahedral geometry in the low values recorded for (5) and (6). The $\mathrm{Fe}^{\mathrm{II}}$ cryptates (3) and (4) 


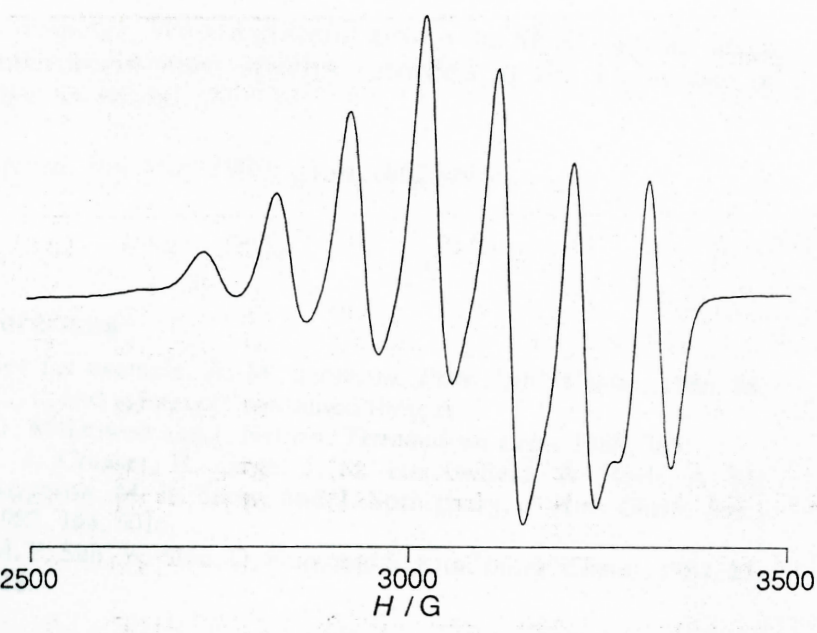

Figure 2. ESR spectrum of (9) as a dimethylformamide (dmf) glass at $113 \mathrm{~K}$.

however, are in the ${ }^{1} \mathrm{~A}_{\mathrm{g}}$ low spin state at ambient temperature, suggesting that distortion from octahedral geometry, in the case of $\mathrm{Fe}^{\mathrm{II}}$, is not large.

The mononuclear $\mathrm{Cu}^{\mathrm{II}}$ complex (8) exhibits the normal axial-type 4-line ESR signal with $g_{\|}(\approx 2.28)>g_{\perp}(\approx 2.07)$ and $A_{\|} \approx 143 \mathrm{G}\left(1 \mathrm{G}=10^{4} \mathrm{~T}\right)$, indicating extended tetragonal geometry for the co-ordination site.

An interesting observation arises from the isolation of a bi-nuclear copper cryptate $\mathrm{Cu}_{2} \mathrm{~L}^{1}\left(\mathrm{ClO}_{4}\right)_{4}(9)$ when the strontium template is refluxed in an alcohol-acetonitrile solvent with excess of $\mathrm{Cu}^{\mathrm{II}}$ salt. Although elemental analysis suggests a dicopper ${ }^{\mathrm{II}}$ formulation in the solid state, in solution an interesting 7-line ESR $g=2$ signal (Figure 2) is seen, which persists as 7 lines down to $4 \mathrm{~K}$ in the DMF-glass spectrum. $\neq$ The simple 7-line pattern strongly suggests that a mixedvalence $\mathrm{Cu}{ }^{\mathrm{II}} / \mathrm{Cu}^{\mathrm{I}}$ species has been formed via redox transformation, and its persistence to such low temperatures indicates an unusual degree of valence delocalization.

The template Group 2 cryptates are labile and in consequence easily transmetallated. Transition series ions, however, although easily encapsulated via the transmetallation process, appear to become kinetically inert once encapsulated; treatment of [ $\left.\mathrm{CoL}^{1}\right]^{2+}$ with $\mathrm{NaCN}$ (aq.) fails to generate a $\mathrm{Co}(\mathrm{CN})_{2}$ precipitate during several weeks. The aqueous stability of (6) is remarkable for a Schiff's base complex; water is indeed one of the best recrystallisation solvents for this complex.

The encapsulated transition series ions may thus be expected to function as sterically protected kinetically inert redox reagents of the 'innocent' kind. In contrast to Sargeson's hexamino cryptands, ${ }^{5}$ our hexaimino donor set should favour to some degree the adoption of low oxidation states. The $+3 /+2$ couples for cobalt complexes of sar and sep are seen at -200 and $-220 \mathrm{mV}$ respectively (vs. standard calomel electrode, SCE); i.e. some $400 \mathrm{mV}$ less positive than the analogous quasi-reversible couple in (5) (Figure 3). The $+2 /+1$ reduction for cobalt sar and sep complexes is irreversible and occurs at very negative (ca. $-2000 \mathrm{mV}$ ) potential, whereas, as Figure 3 shows, reversible reductions at -830 and $\approx-1380 \mathrm{mV}(v s . \mathrm{Ag} / \mathrm{AgCl})$ are characteristic of $\left[\mathrm{CoL}^{1}\right]^{2+} . \mathrm{On}$

$\ddagger$ The lability of this species at ambient deters us from reporting its apparent solution properties at this stage.

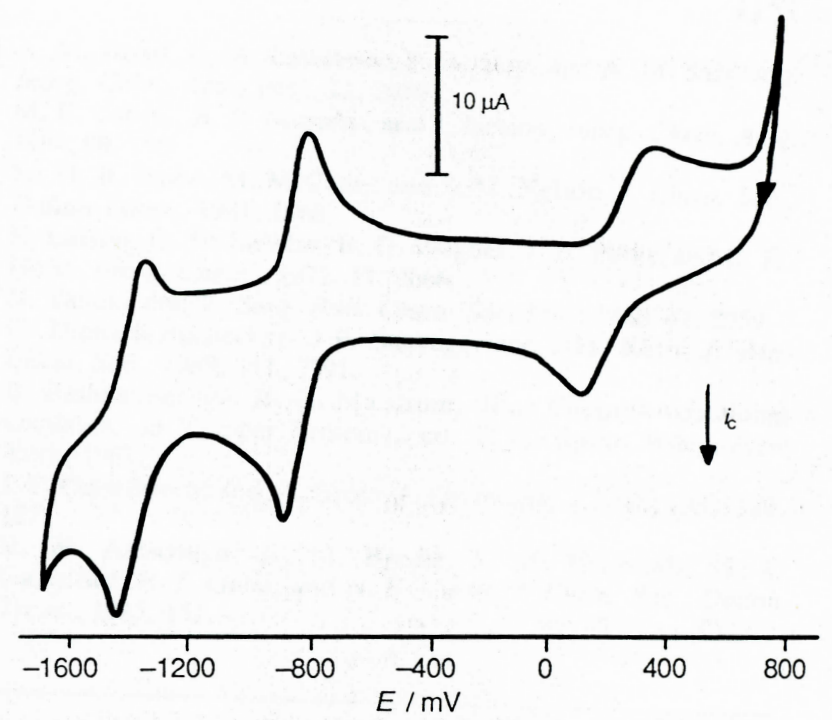

Figure 3. Cyclic voltammograms of (5) in dmf; scan rate $50 \mathrm{mV} \mathrm{s}^{-1}$.

the basis of related work with complexes of macrocyclic, ${ }^{6,7}$ macrobicyclic,${ }^{8}$ chelating, ${ }^{9}$ and catenand ${ }^{10} \mathrm{sp}^{2}-\mathrm{N}$ donors, both these reduction processes may be assumed to be metalcentred. So it does appear that low oxidation states such as $\mathrm{Co}^{\mathrm{I}}$ are stabilised by encapsulation within $\mathrm{L}^{1}$.

A similar inference can be drawn from the appearance of an $\mathrm{M}^{\mathrm{II}}$ reversible reduction wave around $-1.0 \mathrm{~V}$ in the iron(II), nickel(II), and manganese(II) cryptates. The second reversible reduction process observed for (2), (3), (4), and (7) may originate either in $\mathrm{M}^{\mathrm{I}} \rightarrow \mathrm{M}^{0}$ reduction or a metal ionpromoted $\mathrm{M}^{\mathrm{I} L} \rightarrow \mathrm{M}^{\mathrm{I}} \mathrm{L}$ - ligand reduction. ESR experiments are planned to distinguish between the various alternatives.

Oxidation waves are observed at $+1350,820,1170$, and $1220 \mathrm{mV}$ (vs. Ag/AgCl) respectively for $\left[\mathrm{MnL}^{1}\right]^{2+},\left[\mathrm{FeL}^{1}\right]^{2+}$, $\left[\mathrm{NiL}^{1}\right]^{2+}$, and $\left[\mathrm{CuL}^{1}\right]^{2+}$, but only in the case of $\left[\mathrm{FeL}^{1}\right]^{2+}$ is there any hint of reversibility. The potentials recorded in Table 1 are not far removed ${ }^{6,7}$ from those of other mononuclear complexes of $\mathrm{sp}^{2}-\mathrm{N}_{6}$ ligands. The major advantage of $\mathrm{L}^{1}$ in comparison with these flexible macrocyclic ligands lies in the kinetic inertness of the encapsulated metal ion and the enhanced chemical stability towards e.g. hydrolysis of the cryptand ligand.

The positive potential recorded for the $+2 /+1$ reduction in (8) is interesting. Such positive potentials of the order of those seen in blue copper proteins ${ }^{11}$ are commonly associated with a co-ordination environment which favours tetrahedral geometry ${ }^{10}$ and/or involves sulphur donors. ${ }^{12}$ There are advantages to be gained from avoiding the use of S-donors where copper redox processes are involved because such ligands ${ }^{13}$ are often found to be oxidisable at the sulphur site. The tetrahedral geometry enforced on the transition ion site, in Sauvage's innovative strategy, dispenses with the need for $\mathrm{S}$-donors, but for some purposes may overenhance stability of the low oxidation state. We believe that the new copper cryptates described above, which show the borderline $+2 /+1$ stability associated with efficient copper redox catalysis, may prove to be of value as chemically robust redox reagents for effecting mild redox transformations.

We thank DENI for support (to J. H.), and the SERC for contributing to the cost of a Faraday balance and PE $\lambda .9$ 
spectrometer. We are grateful also to the SERC for fast-atom bombardment mass spectra recorded at the University of Wales, Swansea.

Received. 9th May 1990; Com. 0/02049D

\section{References}

1 See for example, A. M. Sargeson, Pure Appl. Chem.. 1986, 58, 1511 , and references contained therein.

2 D. McDowell and J. Nelson, Tetrahedron Lett., 1988, 385.

3 J. J. Creaser, R. Gene, J. M. Harrowfield, A. Herlt, A. M. Sargeson, M. R. Snow, and J. Springborg, J. Am. Chem. Soc., 1982, 104, 6016.

4 M. P. Suh, W. Shin, D. Kim, and S. Kim, Inorg. Chem., 1984, 23, 618.
5 A. M. Bond, G. A. Lawrance, P. A. Ray, and A. M. Sargeson, Inorg. Chim. Acta, 1983, 22, 2010.

6 M. F. Cabral, B. P. Murphy, and J. Nelson, Inorg. Chem. Acta, 1984, 90, 169.

7 M. G. B. Drew, M. McCann, and S. M. Nelson, J. Chem. Soc. Dalton Trans., 1981, 1868.

8 E. Larson, G. N. La Mar, B. E. Wagner, J. E. Parks, and R. H. Holm, Inorg. Chem., 1972, 11, 2666.

9 N. Tanaka and Y. Sato, Bull. Chem. Soc. Jpn., 1968; 41, 2059.

10 C. Dietrich-Buchecker, J-P. Sauvage, and J-M. Kern, J. Am. Chem. Soc., 1989, 111, 7791.

11 B. Reihammer and B. G. Malstrom, 'Blue Copper-containing Oxidases,' in 'Copper Proteins,' ed. T. G. Spiro, Wiley, New York, 1981.

12 J. P. Gisselbrecht and M. Gross, J. Electroanal. Chem., 1981, 127, 127.

13 E. W. Ainscough, A. M. Brodie, J. M. Husbands, G. J. Gainsford, E. J. Gabe, and N. F. Curtis, J. Chem. Soc., Dalton Trans., 1985, 151.

\title{
Novel Synthesis of Indolizines
}

\author{
Nagatoshi Nishiwaki, Kiyonori Furuta, Mitsuo Komatsu, and Yoshiki Ohshiro* \\ Department of Applied Chemistry, Faculty of Engineering, Osaka University, Yamadaoka 2-1, Suita, Osaka 565, \\ Japan
}

2-Phenylethnylpyridine reacted with dimethyl acetylenedicarboxylate (DMAD) in the presence of a proton source such as an alcohol to give indolizines having methoxycarbonyl groups at the 2- or 2,3-positions in high yields.

We previously reported the direct ethynylation of pyridines by the Reissert-Henze type reaction. ${ }^{1}$ In order to use pyridines having an ethynyl group in the synthesis of bicyclic pyridines, we studied the reaction of acetylenylpyridines with dimethyl acetylenedicarboxylate (DMAD). Acheson and Bridson had tried this reaction, but they obtained only unidentified materials. ${ }^{2}$ In contrast, we have now found that this reaction gave indolizine derivatives.

A benzene solution $(10 \mathrm{ml})$ of 2-phenylethynylpyridine (1a) $(1 \mathrm{mmol}), \mathrm{MeOH}(20 \mathrm{mmol})$, and DMAD $(2 \mathrm{mmol})$ was stirred at room temperature for one day. The mixture was concentrated and chromatographed $\left(\mathrm{SiO}_{2}\right.$; hexane-AcOEt, $95: 5)$ to give 1 -( $\alpha$-methoxybenzyl)-2-methoxycarbonylindolizine (2a) as a pale-yellow oil in $85 \%$ yield.

The structure of (2a) was determined from spectral and analytical data. $\dagger$ Measurement of ${ }^{1} \mathrm{H}-{ }^{1} \mathrm{H}$ 2D NMR nuclear Overhauser enhancements (NOEs) supported the structure; the correlations observed are shown in Figure 1 . Since it is known that quinolizine derivatives may be obtained from pyridine and DMAD ${ }^{3}$ the quinolizine (3) is an alternative structure for the product. However, this possibility was easily excluded by observation of a doublet $\mathrm{sp}^{3}$ carbon signal at $\delta 74.3$ in the ${ }^{13} \mathrm{C}$ NMR spectrum.

Other dipolarophiles such as methyl acetylenemono-

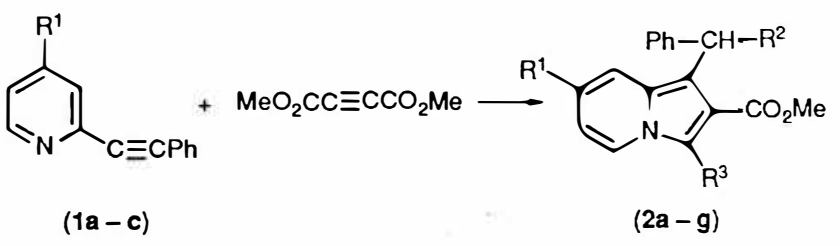

Scheme 1. Conditions: Additive, benzene, room temp., 1 day. carboxylate, dimethyl maleate, and $\mathrm{N}$-phenylmaleimide were not reactive under similar conditions. The present method was also applicable to substituted acetylenylpyridines. The acetylenylpyridines (1b) and (1c) gave the corresponding indolizine derivatives (2e) and (2f) in moderate yields.

In the absence of an alcohol, the reaction of the pyridine (1a) with DMAD in benzene or tetrahydrofuran (THF) became more complicated. Thus, several alcohols were studied as a proton source, which seems to be essential for this reaction. With EtOH and $\mathrm{Pr} \mathrm{iOH}$, the reaction proceeded similarly and formed the corresponding products (2b) and (2c), respectively. In the case of $\mathrm{Bu}^{t} \mathrm{OH}$, demethoxycarbonylation at the 3-position did not occur and (2d) was isolated. When $\mathrm{MeOD}$ was used instead of $\mathrm{MeOH}$, the product (4) deuteriated at the benzyl position and the 3-position of the indolizine skeleton was obtained in $98 \%$ yield, showing that these two protons come from the alcohol. It is noteworthy that the reaction in the presence of dimethyl malonate instead of an alcohol resulted in carbon-carbon bond formation at the benzyl position and gave the indolizine $(\mathbf{2 g})$.

On heating the 2,3-bis(methoxycarbonyl) derivative (2d) in $\mathrm{MeOH}$, substitution at the benzyl position occurred to give the analogue (2h). Generation of $\mathrm{MeO}^{-}$in the reaction of phenanthridine and DMAD in $\mathrm{MeOH}$ has been reported, ${ }^{4}$ but further treatment of (2h) with $\mathrm{MeONa}(2$ equiv.) caused no

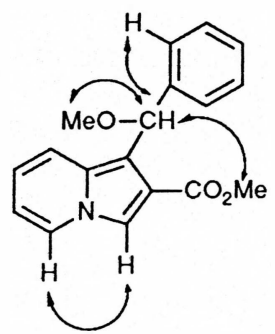

Figure 1. NOE correlations in (2a). 